\title{
MORE TRAFFIC MEANS MORE ACCIDENTS? THE CASE OF FRENCH NICE HIGHWAY
}

\author{
Didier Grimaldi \\ Dept of Management, La Salle Faculty, Ramon Llull University, 08022 Barcelona Spain \\ Didier.grimaldi@salle.url.edu
}

Commission IV

KEY WORDS - Traffic congestion; traffic accident; smart city; pollution; highway.

\begin{abstract}
This paper argues the relationship between traffic volume and accidents in highway sections. The paper shows the French city of Nice case and the analysis of the M6098 highway connecting the city to the airport. Amongst the different variables that are linked to traffic volume we select, explaining our choice, the NO2 pollution parameter. We collect a large volume of data from a long period of time between 2012 and 2014 that we collect from the national road traffic center. Our results show it does exist a relationship between traffic volume and accidents with a stronger factor during the weekdays. A long debate exists in the Literature concerning this possible correlation and our paper suggests the confirmation for one of the different positions expressed. Our conclusions help city Managers in their task to understand the conditions of urban living and transport. They are additional inputs to define local policies in order to improve the efficiency of private transport and prepare future smart cities.
\end{abstract}

\section{INTRODUCTION}

According to the Global Health Observatory (2014), the global urban population is expected to grow by $1.84 \%$ each year between 2015 and 2020, and then by $1.63 \%$ until 2025 . By 2050 , urban areas are predicted to account for $70 \%$ of the world's population (Woods \& Goldstein, 2014). This poses significant challenges related to economy sustainability, environment, and social factors. To overcome them, cities need to improve their capacity and services to maximize the quality of life for its citizens (Kourtit, Nijkamp, \& Partridge, 2015) keeping up with the rapidly changing global urban environment. Central in reaching such a goal is the new technologies and the re-evaluation of governance and policy models, in order to enable innovative and sustainable transport solutions. In our paper, we propose to join our efforts into this re-engineering exercise understanding the relationship between traffic congestion and traffic accidents in highways. Even if it has been largely described in the past (e.g. Martin, 2002; Wang, Quddus, \& Ison, 2009; Shefer, 1994), a clear agreement is missing on how these two variables are correlated together. To respond to this objective, we select (justifying it) the case of French highways and more precisely the zone of Nice city in the Southeast of France. This case study allows us to test our hypothesis. Our conclusion aims at supporting city Managers in their task to improve the efficiency of private transport and prepare the future smart cities. However, the configuration of Nice a sunny and coast medium-size city, restrincts the generalization of our findings.

\section{THEORETICAL BACKGROUND}

Petridou \& Moustaki (2001), Chan \& Singhal (2015), Young \& Regan (2007), and Stutts et al. (2001) state that around $40 \%$ of the accidents in the USA roads is due to distracted drivers. One fourth of the main causes is due to an outside person, something on the road or an unexpected occurance like another accident. Amongst these objects, they stress that mobile phone usage while driving is the most common distraction following by the search of a parking slot. However, they don't analyze their possible effects on the traffic congestion. Ten years later, IBM (2015), based on an analysis of twenty international cities, concludes that cruising i.e., drivers circulating around a free space create $30 \%$ of traffic congestion but doesn't demonstrate the impact on traffic accidents.

It does not exist a large consensus on the relationship between traffic density and traffic accidents. We note that two different theories are present in the Literature. On one hand, Martin (2002) using observations from $2.000 \mathrm{~km}$ of French interurban motorways in a two-year period examines the link between crash rate and hourly traffic flow. Defining traffic volume as the number of cars per hour, he concludes that crash incidence rate increases steadily as traffic volume increase. However, the severity of the incidence is greater at nighttime, when traffic is lighter. His result illustrates that traffic light is a safety problem in the aim to reduce the frequency of accidents and their severity. Shefer (1994) analyzing inter-urban road sections and highways, adds that heavy congestion results in slower traffic, more air pollution and slightly more 
accidents, but less deadly traffic accidents. Further, he defines this relationship as a U-shaped pattern, where accidents involving heavy injuries and fatalities tend to decrease as the traffic volume increase. He also points out the environmental impact of traffic congestion, stating that pollution from cars is higher when cars drive slower.

On the other hand, Wang et al. (2009) apply a series of statistical methods to examine the relationship between traffic congestion and road accidents, on the M25 motorway in England. They conclude that traffic congestion has little or no impact on the frequency of traffic accidents, regardless of severity level. They reject therefore the U-shaped relationship theory proposed before by Shefer (1994). They add that further research is needed to fully understand the effect traffic congestion has on road accidents. In our paper, we propose to cover this gap analysing the relationship between traffic accidents and traffic density in highway.

\section{Methodology}

So as to analyze this unresolved question, we have conducted an empirical qualitative research following a case study approach. We use the case of French highways where a profound analysis can be performed since the traffic accidents information is kept available for a long period (two years between 2012 and 2014). "Data.gouv.fr" is the official French government platform that offers records of traffic accidents. We decide also to consider NO2 pollution as a proxy of traffic congestion. Indeed, several studies (e.g. Ross et al., 2006; Zhang, Guan, Leaderer, \& Holford, 2013; Rose, Cowie, Gillett, \& Marks, 2009) indicate that NO2 rate can be predicted based on traffic density or average daily traffic. Others (e.g. Gilbert, Woodhouse, Stieb, \& Brook, 2003; Zhang et al., 2013) add that NO2 measurements decline according to the distance from high traffic roads.

"Air Paca" is a regional government initiative from the southern of France and provides the atmospheric conditions of the whole area. "Air Paca" has several sensors strategically installed to measure the pollution generated by the traffic in the sensitive locations across the French Riviera. In our paper, we use the city of Nice, the capital of the alpes-maritimes department of the french riviera where the information on traffic accidents and $\mathrm{NO} 2$ pollution are both captured with a high level of quality. "Air Paca" has four air pollution captors installed in Nice. (1) Right outside the urban city center, (2) along the roadway M6098 connecting the city to the airport, (3) in a suburban area outside the city center and (4) close to the airport, categorized as industrial sensor. We opt to use measurement from the sensor "Promenade" (2), located on the road M6098 since its location makes it consistent with the purpose of our study. We collect data for 3 years (2012-2014) that we consolidate considering the day as the unit of measure.

\section{RESULTS}

After analyzing visually, the gathered data, we observe two different traffic patterns in terms of volume. We then build two models splitting the weeks between from one side: Monday to Friday and on the other side Saturday and Sunday. We then run diverse regression analysis to evaluate the possible correlation between the accidents rate and the pollution density in NO2. The table 1 covers our findings. It shows that traffic accidents and $\mathrm{NO} 2$ pollution rate are positively correlated. NO2 factor justifies $41 \%$ of the car crashes variance during the weekends and 51\% during the weekdays.

$\begin{array}{lll}\text { Measure } & \text { weekend } & \text { weekdays } \\ \text { Intercept } & -21.402 & -9.475 \\ \text { NO2 } & 1.359 * * * & 1.442 * * * \\ \text { R-squared } & .413 & .508 \\ \text { Adjusted R-squared } & .408 & .501 \\ \mathrm{~N} & 138 & 69 \\ * * * \mathrm{p}<.001 & & \end{array}$

Table 1: Results of simple linear regression analysis

\section{Discussion \& Conclusion}

When testing the relationship between traffic volume and accidents in Nice, our results indicate a strong correlation during weekdays, and a slightly weaker correlation during weekends. By measuring the volume of circulating cars from the M6098 sensor, our method selects a site that we consider representative for the highway traffic volume in Nice, connecting the city center with the suburban area

We must be very careful about interpreting evidence as causal, when it only shows a correlation. A causal interpretation is only possible if the independent variable (NO2 pollution) is exogenous (randomly assigned). We need to assume by default that variables are endogenous. They are not randomly assigned, but the product of something else - the dependent variable itself (expecting a high future income encourages you to get a degree today - reverse causality), or a third variable that also affects the dependent variable (high ability makes you more willing to get a degree - omitted variables). Fortunately, there are now clever techniques to separate causality from correlation such as regression discontinuity. In our case, since the $\mathrm{NO} 2$ correlation improves significantly (from 1.359 to 1.442 ) by analyzing separately weekends and weekdays (figure 1), it shows a regression discontinuity, in other words, that an increased NO2 pollution causes higher traffic accidents.

Our results confirm the hypothesis raised demonstrating the existence of a relationship between traffic accidents and traffic density in highway section. They corroborate the studies of Martin (2002) and Shefer (1994) even if we don't observe any specific U-pattern despite our large volume of collected data. We understand that a high rate of vehicles on the road surely decreases their speed but increases in parallel their probability of collision. Our findings suggest that the second factor has a larger importance than the first one. However, we 
can argue that the speed of vehicles movement depends not only on the number of cars in the road but also on the size of the highway section that varies between two and four lanes in France and more largely in Europe.

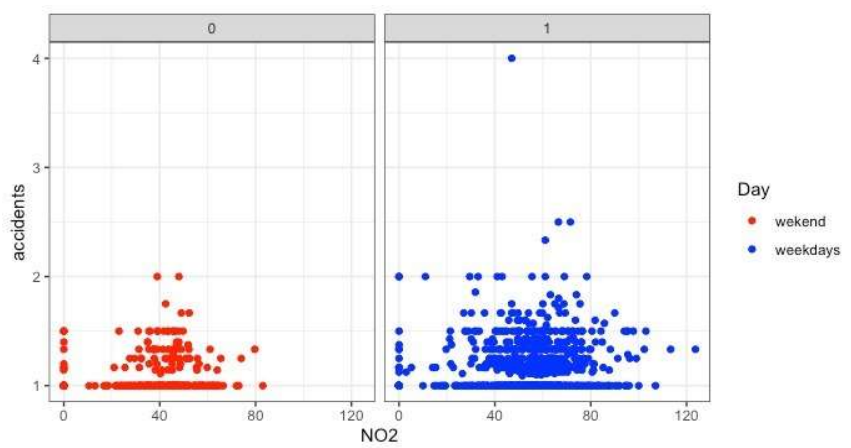

Figure 1: Regression discontinuity during the week

Systematic observations of 82 Swedish road sections identify four clusters using the variables of velocity limitation and sizes of lanes on the road (Hiselius, 2004). Their analysis concludes that only the cluster corresponding on a speed limit set to $70 \mathrm{~km}$ /hour and a width between six and nine meters is increasing in line with traffic volume. For other types of road, wider or with a higher speed limit, the accident rate shows little or no change. This finding brings a new contribution on the discussion. Indeed, the size of the road seems to moderate the relationship between traffic accidents and density. Our study has selected a three-lane highway with a limitation of $70 \mathrm{~km} /$ hour. The width of the section is also between 6 and 9 meters and indeed, we get the results of correlation between accidents and density in accordance with the highway characteristics described by Hiselius (2004). Moreover, we suggest a similar analysis could be performed to explain why our conclusions seem to disagree with Wang et al. (2009)'s results. Further investigation could determine if the size of the road may justify the divergence of points of view.

Finally, we believe that the results of Nice city can be of interest to city managers in their task to improve the transport quality and safety along with the general urban living services. However, we stress that the Nice's localization; a coastal city of $300 \mathrm{k}$ residents could limit the stricto-sensu extrapolation of our results to other cities.

\section{REFERENCES}

Chan, M., \& Singhal, A. (2015). Emotion matters: Implications for distracted driving. Safety Science, 72, 302309. doi:10.1016/j.ssci.2014.10.002

Gilbert, N. L., Woodhouse, S., Stieb, D. M., \& Brook, J. R. (2003). Ambient nitrogen dioxide and distance from a major highway. Science of the Total Environment, 312(1-3), 43-46. doi:10.1016/S0048-9697(03)00228-6

Global Health Observatory (GHO) data. (2014). World Health Organization. Retrieved September 20, 2015, from http://www.who.int/gho/urban_health/situation_trends/urban_population_growth_text/en/

Hiselius, L. W. (2004). Estimating the relationship between accident frequency and homogeneous and inhomogeneous traffic flows. Accident Analysis \& Prevention, 36(6), 985-992. doi:10.1016/j.aap.2003.11.002

IBM. (2015). IBM Global Parking Survey: Drivers Share Worldwide Parking Woes.

Kourtit, K., Nijkamp, P., \& Partridge, M. D. (2015). Challenges of the New Urban World. European Planning Studies, 20(1), 1-17. doi:10.1080/09654313.2012.716242

Martin, J. L. (2002). Relationship between crash rate and hourly traffic flow on interurban motorways. Accident Analysis and Prevention, 34(5), 619-629. doi:10.1016/S0001-4575(01)00061-6

Petridou, E., \& Moustaki, M. (2000). Human factors in the causation of road traffic crashes. European Journal of Epidemiology, 16, 819-826.

Rose, N., Cowie, C., Gillett, R., \& Marks, G. B. (2009). Weighted road density: A simple way of assigning traffic-related air pollution exposure. Atmospheric Environment, 43(32), 5009-5014. doi:10.1016/j.atmosenv.2009.06.049

Ross, Z., English, P. B., Scalf, R., Gunier, R., Smorodinsky, S., Wall, S., \& Jerrett, M. (2006). Nitrogen dioxide prediction in Southern California using land use regression modeling: potential for environmental health analyses. Journal of Exposure Science \& Environmental Epidemiology, 16(2), 106-14. doi:10.1038/sj.jea.7500442

Shefer, D. (1994). Congestion, air pollution, and road fatalities in urban areas. Accident; Analysis and Prevention, 26(4), 501-9. doi:http://dx.doi.org/10.1016/00014575(94)90041-8

Stutts, J. C., Reinfurt, D. W., \& Rodgman, E. A. (2001). The role of driver distraction in crashes: an analysis of 1995-1999 Crashworthiness Data System Data. Annual Proceedings / Association for the Advancement of Automotive Medicine. Association for the Advancement of Automotive Medicine, 45, 287-301.

Wang, C., Quddus, M. a., \& Ison, S. G. (2009). Impact of traffic congestion on road accidents: A spatial analysis of the M25 motorway in England. Accident Analysis \& Prevention, 41(4), 798-808. doi:10.1016/j.aap.2009.04.002

Woods, E., \& Goldstein, N. (2014). Smart Cities: Smart Technologies and Infrastructure for Energy, Water, Transportation, Buildings and Government. Navigant Research.

Zhang, L., Guan, Y., Leaderer, B. P., \& Holford, T. R. (2013). Estimating daily nitrogen dioxide level: exploring traffic effects. The Annals of Applied Statistics, 7(3), 1763-1777. doi:10.1214/13-AOAS642 